\title{
Sequelae to pneumoencephalography
}

\author{
Y. S. WHITE, D. S. BELL, AND R. MELLICK \\ From the Psychiatric Research Unit, Callan Park Hospital, Rozelle 2039, Australia
}

SUMMARY Fifty patients were examined clinically and neurologically for seven days after pneumoencephalography. Headache was present in $78 \%$, neck stiffness in $34 \%$, pyrexia in $38 \%$, vomiting in $34 \%$, tachycardia in $74 \%$, a change in the level of consciousness in $18 \%$, and abnormal neurological signs in $30 \%$. Of the 13 patients with epilepsy, there was an increased frequency of seizures in four, associated with increased EEG epileptiform activity in three. EEG abnormality either appeared or increased in $74 \%$ of cases on the second day after the air study. A mechanism for the production of these sequelae is proposed. It is concluded that these findings indicate that in most cases an organic brain syndrome follows pneumoencephalography.

Since its introduction in 1919, pneumoencephalography has been observed to produce a wide range of side-effects: Bohn (1937), in a study of 1,000 cases, reported headache, vomiting, pyrexia, tachycardia, changes in blood pressure, stiffness in the neck, and mental confusion. Changes in the constituents of cerebrospinal fluid were reported by Schwab and von Storch (1937), Levinson, Kaplan, and Cohn (1939), Wartenberg (1939), Robertson (1957), Marrack, Marks, and Couch (1961), Taveras and Wood (1964), and Dykes and Stevens (1970). Electroencephalographic (EEG) abnormalities were found by Riehl and Ansel (1969) and Hammer and Klingler (1969). Alterations in ventricular size on radiological examination, present for varying periods after pneumoencephalography, were observed by Robertson (1947), Stallworthy and Savage (1955), Le May (1967), and Booker, Matthews, and Whitehurst (1969).

These observations suggest that in many cases pneumoencephalography results in sequelae consistent with an organic brain syndrome. We will use the definition of the organic brain syndrome proposed by Lipowski (1967) - that is, a state of cerebral insufficiency in which there is a reduction in the level of cognition and a characteristic slowing of the EEG. Our study was designed to delineate the clinical features of the post-pneumoencephalography syndrome.

\section{METHODS}

From a consecutive series of 54 patients undergoing pneumoencephalography, the 50 to be described weres followed for a minimum of seven days during which $\stackrel{\vec{Q}}{\mathrm{Q}}$ time there was no other change in their management, four being omitted for the following reasons: two because of failed pneumoencephalograms, oneo because of unavoidable discharge on the day after pneumoencephalography, and one because of un avoidable changes in medication in the post-pneumoencephalography period. The ages of the 50 patients ranged from 13 to 74 years; 29 were male and 21 female. All the patients were investigated at the Psychiatric Research Unit, which provides a neurological and neurosurgical service to the psychiatric hospitals of New South Wales.

Forty-four patients were cooperative enough to allow pneumoencephalography to be performed under neuroleptanalgesia; after premedication with sodium pentobarbitone $100-200 \mathrm{mg}$, droperidol 15-50 mg and fentanyl 75-200 $\mu \mathrm{g}$ were administered. Six patients were uncooperative or medically unwell and for this reason were given a general anaesthetic, initiated with thiopentone sodium and relaxants and continued after endotracheal intubation with nitrous oxide/oxygen. In these latter cases the premedication used was omnopon and scopolamine or pethidine hydrochloride and atropine.

The volume of air injected into the ventricles by the lumbar route varied between 35 and $50 \mathrm{ml}$. In 28 cases a cerebrospinal fluid sample was obtained before and after the injection of air and these samples were examined as soon as possible for protein, glu- 
cose, chloride, and cells. In addition the cerebrospinal fluid was cultured and its Wassermann reaction determined. As the results conformed with the cerebrospinal fluid changes that have already been documented in the literature, a single analysis was made of each patient's combined specimens for the rest of the series.

The patients were kept in bed for three days and were interviewed and examined daily for seven days after pneumoencephalography. Particular attention was paid to headache, nausea, vomiting, pain in the back, fever, level of consciousness, blood pressure, pulse rate, and any changes in the pre-existent epilepsy.

An EEG was taken on the second and eighth day after the air study or as close as possible to these time intervals and a blind comparison made between these and the EEG performed before the procedure. During the observation period, changes in medication and any other procedure which could have affected the EEG were avoided.

A lateral radiograph of the skull was taken every day until the air bubble in the lateral ventricle was less than $1 \mathrm{~cm}$ in width. A smaller air bubble could not be measured accurately. The period during which the air over the cortex could be demonstrated in the plain film was recorded.

\section{RESULTS}

Headache lasting one to nine days occurred in 39 of the 50 patients and vomiting for one to five days in 17 patients. Nine patients had vomiting on the first day only and four of these had omnopon and scopolamine as premedication for general anaesthesia. Neck stiffness was found on examination in 17 patients from the first to the seventh day. Pyrexia was recorded in 19 cases for one to two days, the maximum being $39^{\circ} \mathrm{C}$. One patient with pyrexia of $38^{\circ} \mathrm{C}$ for four days was subsequently found to have a thrombosis in the deep veins of one leg. A tachycardia of $90 /$ min or greater occurred in 37 patients and lasted one to four days. In all except three the rate was greater than $100 / \mathrm{min}$. Six patients were hypertensive for 1 to 12 hours after the air study and three became hypotensive during this period. One of the latter had been given parenteral chlorpromazine for sedation. In 15 cases, at least one of the following neurological signs appeared in the period from the first to the seventh day: unequal pupils, expressive dysphasia, pyramidal or extrapyramidal system involvement. Nystagmus in one patient sug- gested degenerative cerebellar disease and improved after the air study, disappearing by the seventh day of observation.

In eight patients clouding of consciousness occurred or was aggravated after pneumoencephalography. Confusion or incontinence was present in four patients for one day and in another three confusion together with incontinence for three to five days and one patient became drowsy.

Three EEG records were obtained in each of 41 cases. In six cases only one record was obtained after the air study. In three either the pre- or postpneumoencephalography EEG was not done. In 34 cases an EEG abnormality either appeared or increased in the week after the air study. In most cases the abnormalities, were more marked on the second day and improved or resolved by the eighth. The changes consisted characteristically of a decrease of the order of $1-2 \mathrm{~Hz}$ in the frequency of the posterior dominant rhythm and the appearance or increase to a moderate degree of background slow wave activity in the theta and delta range. Eight cases showed no change in the EEG and in five there appeared to be a decrease in the EEG abnormality.

Abnormalities with apparent localizing significance were misleading. In five a focal abnormality appeared for the first time in the postpneumoencephalography record, but in four of these the known cerebral pathology was diffuse and generalized-for example, generalized cerebral atrophy associated with senile dementia. A

TABLE 1

DURATION AIR DETECTED RADIOLOGICALLY AFTER PNEUMOENCEPHALOGRAPHY

\begin{tabular}{|c|c|c|c|c|}
\hline \multirow[b]{2}{*}{$\begin{array}{c}\text { Duration } \\
\text { (days) }\end{array}$} & \multicolumn{2}{|c|}{$\begin{array}{l}\text { Patients with } \\
\text { normal air } \\
\text { studies } \\
(n=20)\end{array}$} & \multicolumn{2}{|c|}{$\begin{array}{l}\text { Patients with } \\
\text { radiological diagnosis } \\
\text { of cerebral atrophy } \\
\quad(n=30)\end{array}$} \\
\hline & $\begin{array}{l}\text { Cortical* } \\
\text { air }\end{array}$ & $\begin{array}{l}\text { Ventricular } \\
\text { filling }\end{array}$ & $\begin{array}{c}\text { Cortical } \\
\text { air }\end{array}$ & $\begin{array}{l}\text { Ventricular } \\
\text { filling }\end{array}$ \\
\hline $1-2$ & 11 & 3 & 9 & 1 \\
\hline $3-4$ & 3 & 7 & 12 & 3 \\
\hline $5-6$ & 0 & 4 & 4 & 9 \\
\hline $7-8$ & 0 & 4 & 4 & 12 \\
\hline $9-10$ & 0 & 1 & 1 & 2 \\
\hline $11-12$ & 0 & 0 & 0 & 1 \\
\hline $13-14$ & 0 & 1 & 0 & 2 \\
\hline
\end{tabular}

* Six patients did not have radiologically detectable air over the cortex. 
lateralized EEG abnormality appeared in two cases, both with generalized cerebral pathology. On the other hand, the increase in bilateral EEG abnormality obscured the localizing sign in one case of temporal lobe epilepsy with a lateralized EEG abnormality.

The five subjects whose EEGs improved temporarily included a patient with focal epilepsy whose focal discharge disappeared during the week after the air study and a case of epilepsy in which the focal discharge and the background slow wave abnormalities persisted unchanged, but the posterior dominant rhythm increased in frequency.

The pneumoencephalograms revealed that 20 patients had normal air studies and 30 had cerebral atrophy. Table 1 shows that cortical and ventricular air were present for a longer period in those who had cerebral atrophy. The one patient with an apparently normal pneumoencephalogram, who had ventricular air present for 14 days, had had neurosurgical treatment for a temporal lobe cyst approximately 13 years previously.

There was no significant difference in the incidence or duration of headache between those patients with normal pneumoencephalograms and those with cerebral atrophy and similarly no difference in incidence of overall EEG abnormality. However, there was significantly less vomiting in those with cerebral atrophy.

There were 13 patients with epilepsy. Of these, one had a decrease in the frequency of seizures for the period of observation and in four the frequency increased. Three of the latter showed an increase of epileptiform activity in the EEG recorded on the second day after pneumoencephalography.

Cerebrospinal fluid examination revealed a decrease in the protein concentration of the sample taken after the injection of air in 15 out of 28 cases (range 1 to $13 \mathrm{mg} \%$ ). In five there was an increase of 1 to $6 \mathrm{mg} \%$. There was no change in eight. An increase in the number of white cells in the cerebrospinal fluid after the injection of air was found in 14 cases, in seven there was a decrease, and in seven there was no change.

\section{DISCUSSION}

The findings in this study indicate that the common sequelae of pneumoencephalography are headache, neck stiffness, nausea and vomiting, pyrexia, tachycardia, alteration in the frequency of fits, change in the level of consciousness, appearance of neurological signs, and EEG abnormalities.

Headache was a common complaint. Robertson (1957) claimed that headache is rare after pneumoencephalography. Taveras and Wood (1964) found that the absence of headache after pneumoencephalography was related to the presence of cerebral atrophy, but we were unable to confirm this.

All patients with neck stiffness also had headache and most of these did not notice any stiffness. Bohn (1937) and Schwab and von Storch (1937) suggested that neck stiffness after pneumoencephalography is associated with an aseptic meningeal reaction resulting from the presence of air in the subarachnoid spaces.

Pyrexia lasting one to two days has been noted by Bohn (1937), Le May (1967), and Clark, Obenchain, Hanafee, and Wilson (1970). In ouro series there was no correlation between the? 을 presence of pyrexia and the occurrence of neck 2 stiffness.

Nausea and vomiting occurring only on the first day after the air study was in some cases no doubt due to the premedication or the anaes 윽 thetic. Omnopon is well recognized as causing nausea and vomiting in susceptible persons (Dripps, Eckenhoff, and Vandam, 1961): of the six patients given omnopon and scopolamine, four had vomiting for one day only. Although fentanyl may possibly cause vomiting, the other drugs used in neuroleptanalgesia are antiemetic.

When correction was made for those patients given general anaesthesia, the absence of vomiting was significantly more common in those with cerebral atrophy $(P<0.05)$. We cannot suggest an explanation for this finding. The eight cases of vomiting for periods longer than one day were possibly associated with organic cerebral changes after pneumoencephalography.

The occurrence of tachycardia in $74 \%$ of patients was surprisingly common; in Bohn's (1937) series of 1,000 patients it was noted in only $33 \%$. The only significant fluctuations in blood pressure would appear to have been associated with the anaesthesia or, in one case of hypotension, with the administration of parent- 
eral chlorpromazine, which can lower the blood pressure (Goth, 1964).

Neurological signs that appeared temporarily after the air study were varied and showed no particular pattern. Only impairment of consciousness would seem to have been reported previously: Hammer and Klingler found this in 29 of 92 patients in the 24 hours after pneumoencephalography.

The appearance or increase of EEG abnormality to a mild or moderate degree in 34 of 47 cases further confirms the occurrence of cerebral dysfunction after the air study and is consistent with previous reports (Hammer and Klingler, 1969; Riehl and Ansel, 1969). An increase in the frequency of epileptic seizures was associated with an increase in EEG epileptiform activity in four of five cases, but otherwise the changes in

TABLE 2

LEVEL OF CONSCIOUSNESS RELATED TO CEREBRAL ATROPHY

\begin{tabular}{lcc}
\hline & $\begin{array}{c}\text { No clouding of } \\
\text { consciousness } \\
(n=42)\end{array}$ & $\begin{array}{c}\text { Clouding of } \\
\text { consciousness } \\
(n=8)\end{array}$ \\
\hline $\begin{array}{l}\text { Normal pneumoencephalogram } \\
\begin{array}{l}\text { Cerebral atrophy as } \\
\text { radiological diagnosis }\end{array}\end{array}$ & 19 & 1 \\
\hline
\end{tabular}

this series were non-specific. In particular, when a focal or lateralized abnormality appeared for the first time, this did not have localizing significance. In fact, the increase in generalized EEG abnormality in one case actually obscured a lateralized epileptiform discharge. Our finding of false localizing signs in the post-pneumoencephalography records is consistent with the bulk of the literature, reviewed by Riehl and Ansel (1969), but contrary to their observations.

The presence of cerebral atrophy reduced the likelihood of nausea and vomiting. There was a trend for cerebral atrophy to be associated with impairment of consciousness (Table 2), but this did not reach the level of statistical significance. Lipowski (1967) has noted that, in general, there is an increased predisposition to the develop- ment of an organic brain syndrome in people aged 50 years and over and in those with cerebral damage. All of our eight patients with impairment of consciousness had one or both of these features. In fact seven had cerebral atrophy. This is also relevant to the findings of Potthoff (1970), who reported the occurrence of a 'psychoorganic syndrome' occurring after pneumoencephalography in a group of patients with Parkinson's disease, $85.3 \%$ of whom were found to have cerebral atrophy.

One patient had a transient but striking improvement in her mental state.

\section{CASE HISTORY}

A woman, aged 47 years, a known alcoholic, had been admitted to hospital five months previously in hepatic coma. She was unable to give any history, but was known to have had episodes of delirium tremens in the past. After recovery from the hepatic coma, she was regarded as suffering from dementia. Physical examination revealed multiple spider naevi on her face and shoulders, a tender firm hepatomegaly, evidence of peripheral neuropathy in the lower limbs, and bilateral extensor plantar responses. She had frequent attacks of unexplained fever, during which she would become even more confused, but the liver function tests, lumbar puncture, and cerebrospinal fluid showed no abnormality. The EEG on admission showed a low voltage $11 \mathrm{~Hz}$ alpha rhythm.

Before the air study the patient was hyperactive. Approximately two weeks after admission she had several grand mal seizures and was started on phenytoin sodium $100 \mathrm{mg}$ tds and methylphenobarbitone $60 \mathrm{mg}$ tds. Pneumoencephalography was performed two days later under general anaesthesia after premedication with omnopon and scopolamine. The air study revealed slight dilatation of the ventricular system and excess cortical air over both hemispheres indicative of diffuse cerebral atrophy. For four days after pneumoencephalography the patient was more cooperative, answered questions in a rational manner, and commented relevantly about events occurring in the ward around her. On the fifth day after her air study she again reverted to her confused, noisy, and verbally aggressive behaviour. The cerebrospinal fluid examination was normal.

During the period of improvement, her EEG showed a slight reduction in the frequency of the alpha rhythm and an appearance of background delta activity of higher amplitude in the left temporal region. Eight days after the air study long runs of 
spike and wave discharge with a repetition frequency of one per second appeared, of higher amplitude on the right side.

The occurrence of a transient improvement in mental state after pneumoencephalography does not seem to have been documented. The alteration may have been associated with the treatment of the epilepsy, but against this is the fact that the patient reverted to her previous mental state even though the medication remained unchanged. The change in the EEG during the stage of improvement suggested that this patient had been affected by the organic brain syndrome following pneumoencephalography.

About half of the cases examined had a drop in protein concentration in the cerebrospinal fluid after injection of the air. Similar findings have been reported by Schwab and von Storch (1937), Marrack et al. (1961) and Dykes and Stevens (1970). Our finding in 50\% of cases of a white cell pleocytosis after injection of air is consistent with reports from Schwab and von Storch (1937), Davidoff and Dyke (1951), Marrack et al. (1961), and Taveras and Wood (1964).

In patients with cerebral atrophy both cortical and ventricular air were present for longer than in those with normal pneumoencephalograms. The time course of the organic brain syndrome and the presence of air in the cerebrospinal fluid spaces, particularly that in the ventricles, corresponded closely to each other.

The mechanism by which the sequelae to pneumoencephalography are produced may be explained as the consequence of the abrupt and temporary displacement of the brain after the injection of air into the ventricular system. Although the duration of the displacement is short lived, the effect may be prolonged for days by arterial spasm (Dott, 1960), which occurs as a result of stretching and attenuation of the basal perforating arteries. The resultant ischaemia would affect the diencephalon, the midbrain, the archipallium, and the hypothalamus. Ischaemia in this situation clearly may result in impairment of consciousness, alterations of emotional state, and derangements of homeostasis, including those observed in this study-for example, disorders of body temperature, blood pressure, and cardiac function. Some of the neurological signs observed by us may be explained by the fact that the long tracts traversing this zone may also be affected. The stretching of the basal perforating arteries may lead to headache.

We are grateful to Professor L. G. Kiloh for his helpful advice and to the staff of the Psychiatric Research Unit who assisted in the many observations required for this study.

\section{REFERENCES}

Bohn, S. S. (1937). The reactions of patients to encephalography. An analysis of one thousand consecutive cases. Bulletin of the Neurological Institute of New York, 6, 540 568.

Booker, H. E., Matthews, C. G., and Whitehurst, W. R. (1969). Pneumoencephalographic planimetry in neurological disease. Journal of Neurology, Neurosurgery, and Psychiatry, 32, 241-248.

Clark, R. A., Obenchain, T. G., Hanafee, W. N., and Wilson, G. H. (1970). Pneumoencephalography. Comparison of complications in 100 pediatric and 100 adult cases. Radiology, 95, 675-678.

Davidoff, L. M., and Dyke, C. G. (1951). The Norma Encephalogram, 3rd edn. Lea and Febiger: Philadelphia.

Dott, N. M. (1960). Brain, movement and time. Britis Medical Journal, 2, 12-16.

Dripps, R. D., Eckenhoff, J. E., and Vandam, L. D. (1961) Introduction to Anesthesia. The Principles of Safe Practicen 2nd edn. Saunders: Philadelphia.

Dykes, J. R. W., and Stevens, D. L. (1970). Alterations it lumbar cerebrospinal fluid protein during air encephalo graphy. British Medical Journal, 1, 79-81.

Goth, A. (1964). Medical Pharmacology: Principles and Concepts, 2nd edn. Mosby: Saint Louis.

Hammer, B., and Klingler, D. (1969). Veränderungen des Ventrikelsystems und des EEGs 24 Stunden nach Pneumenzephalographie. Wiener medizinische Wochenschrift, 119, 484-488.

Le May, M. (1967). Changes in ventricular size during and after pneumoencephalography. Radiology, 88, 57-63.

Levinson, A., Kaplan, I., and Cohn, D. J. (1939). Changes in the chemistry of cerebrospinal fluid during encephalography. Journal of Laboratory and Clinical Medicine, 25 , 225-237.

Lipowski, Z. J. (1967). Delirium, clouding of consciousness and confusion. Journal of Nervous and Mental Disease, 145 227-255.

Marrack, D., Marks, V., and Couch, R. S. C. (1961). Changes in the lumbar cerebro-spinal fluid during air-encephalography. British Journal of Radiology, 34, 635-639.

Potthoff, P. C. (1970). Psycho-organic syndromes following pneumoencephalography in parkinsonian patients. In Abstracts of Papers Presented, Part I, 5th International Symposium on Stereoencephalotomy, 1970, Freiburg i. Br., p. 21. Edited by T. Riechert, F. Mundinger, R. Hassler, H. T. Wyers, and E. A. Spiegel. International Congress Series No. 217. Excerpta Medica Foundation: Amsterdam.

Riehl, J.-L., and Ansel, R. (1969). EEG changes following pneumoencephalography. Acta Neurologica Scandinavica, 45, 270-276.

Robertson, E. G. (1947). Some physical aspects of encephalography. Brain, 70, 59-74. 
Robertson, E. G. (1957). Pneumoencephalography. Blackwell: Oxford.

Schwab, R. S., and von Storch, T. J. C. (1937). Alterations of the cerebrospinal fluid subsequent to pneumoencephalography. New England Journal of Medicine, 217, 21-24.

Stallworthy, K. R., and Savage, P. P. E. (1955). Clinical aspects of cerebral atrophy revealed by encephalography. New Zealand Medical Journal, 54, 457-463.

Taveras, J. M., and Wood, E. H. (1964). Diagnostic Neuroradiology. Williams and Wilkins: Baltimore.

Wartenberg, R. (1939). Experiences in use of encephalography. Journal of Nervous and Mental Disease, 89, 640649. 